\title{
Water Systems Adaptation: An Australian Cultural Researcher's Perspective
}

\author{
Zoë Sofoulis
}

Published online: 12 December 2012

(C) Springer Science+Business Media Dordrecht 2012

Humans are often regarded as endpoints of water supply systems, their behaviour adjustable to match supply constraints or savings targets. But they are also its starting points: only by means of surveyors, scientists, engineers, governments and technocrats have the waters of Earth come to be systematised into extractable, managed and commodified resources available to meet human-defined objectives, such as improved public health and domestic convenience, in an environment made increasingly uncertain owing to global rearrangements of terrestrial resources (including carbon) by humans.

An early responder to challenges of sustainability and climate change, the water sector developed demand reduction strategies that now provide examples - not all emulable - for adaptation strategies in other sectors. Broad acceptance of 'triple bottom line' sustainability, realisations that experts' solutions are contestable by publics and require their cooperation, and growing responsibilities for demand management involving consumption and consumers, have all highlighted water's social dimensions. But as in the climate change sector, where "The drivers of the carbon based economy are embedded in culture, history and politics, rarely the realm of biophysical scientists" (Bellette 2012, p.5), there is a problematic mismatch between the technical and scientific expertise of water managers and the nature of the demand they attempt to predict and control.

Lacking expertise to deal with the complex social character of water demand, yet seemingly reluctant to recruit it, the water industry mobilised its supply-side experience to formulate resource-centred approaches that emphasised efficiencies, volumes and pricing. This strategy maps the limits of the water supply system, then determines how to change people's water behaviours and household fittings to fit system constraints. Information and technology could turn householders into rational and efficient 'micro-resource managers'; social marketing could convert them into guilty customers who would change their attitudes,

For 'Adaptation and resilience of water systems to an uncertain changing climate' special issue of Water Resources Management

Z. Sofoulis $(\bowtie)$

Adjunct Research Fellow, Institute for Culture and Society, University of Western Sydney,

Sydney, Australia

e-mail: z.sofoulis@uws.edu.au 
modify their water behaviour, and make 'green consumer' choices (Shove 2010; Sofoulis and Strengers 2011).

As Shove (2010) trenchantly notes, this 'ABC' (Attitudes-Behaviour-Choice) model of social change was promulgated by technocrats without involving experts on society, politics, culture or everyday life who could account for the historical, social and technical norms, cultural aspirations and ethical concerns that shape everyday water consumption. Research focussed on perceptions, behavioural intentions, and receptivity to marketing and 'price signals'. Behavioural economics, demographics, market research, and statistical analysis prevailed over interpretive, qualitative, participatory and change-oriented research.

If the basic unit of survival (or adaptation) is not the organism but 'organism plus environment' (Bateson 1972, 483), it is maladaptive to make individuals the primary site of change. Collective socio-cultural innovations must accompany-if not lead-adaptive changes in infrastructures and individuals. Therefore a growing number of social and cultural researchers are advocating more 'culturally intelligent' approaches to adaptation (Sofoulis 2011b, after Ang, 2011), grounded in studies of actual practices and contextualising 'individuals' as participants in cultures, members of societies, and co-occupants of places.

The Australian water industry normally outsources social research to consultants or university researchers (Sofoulis 2011a). Researchers were dissatisfied with the poor quality of questions they were commissioned to investigate, which are typically misaligned with current theories and best research practice, and generically required a big survey. This could be improved were humanities and social science ('HSS') researchers not excluded from early project phases:

You need to start thinking about the social and cultural aspects before the projects are underway so that it can be built into the scope of the project. Too many times it is an afterthought or it is too late for those components to be incorporated. (Social researcher)

This practice of limiting HSS influence on interdisciplinary projects echoes a more general instrumental view of social research as data provider for predictive systems modelling exercises:

The linkages to social science and humanities need to be strengthened, to increase the understanding not only of human impacts, but also to create better models and predictive tools for the future which can map how the environmental space interacts with the human space including taking into account population, behavioural change and resource use (DIISR 2011, p. 17).

HSS researchers struggle getting their knowledge to 'count' because science and quantitative knowledge remain, in one researcher's words, "the norm when it comes to what counts as valuable, relevant and important to decision-makers". As another found, despite "lip service given to human motivations" on a planning team, it was hard translating findings about people's feelings for water and the life force into something acceptable to technical water planners. People trained in positivist science have difficulty accepting the legitimacy of other knowledge paradigms. Positivists are usually epistemological monists - positivist method is simply method. HSS researchers are typically epistemological pluralists who accept there are many understandings of the same phenomenon and different ways of validating knowledge. Whereas most positivists understand valid knowledge is 'objective', derived from the object's properties, most HSS researchers understand knowledge is shaped by the object in relation to the knower's standpoint: the who, how, why, where and when of the knowing. 
Bridging this gulf is not easy, since epistemological monists resist acknowledging other knowledge systems. The burden therefore falls on HSS researchers to translate their findings and recommendations in ways that water experts and policymakers can understand and implement. This journal features a review of new approaches (Pearce, Dessai and Barr) that finds a potential bridge with positivism via grounded theory, a form of empiricism underpinning a number of contemporary qualitative research methods, and a report of the bold experiment by Browne, Medd and Anderson in communicating about the social and material contexts of water consumption via the numbers and statistics water managers prefer.

The water sector's engagement with HSS research is sufficiently advanced that obstacles to the next stage are becoming evident. Other encouraging signs are professional enthusiasm for new paradigms of integrated planning and management, and water managers who escape their disciplinary straightjackets and adopt a multi-dimensional perspective (Sofoulis 2010, pp. 6-7). Tomorrow's managers are taking degrees with options like engineering management and environmental engineering, or double degrees with environmental studies, law, humanities, or social sciences. Even without hiring HSS specialists, the water sector may soon gain improved capacities to collaborate across disciplines, pose relevant social research questions, and translate findings into actions.

Empiricists and pragmatists are at least open to learning from experience, like those Australian water providers who found their economic rationalist model of the customer could not explain people's willingness to comply with harsh water restrictions, acquire 'uneconomic' rainwater tanks, or build social solidarity around these actions during protracted drought. They gained more respect for the public on realising people could act as intelligent partners in co-managing urban water. This emergent partnership model represents a promising starting point for culturally intelligent approaches to water systems adaptation.

\section{References}

Ang I (2011) Navigating Complexity: From cultural critique to cultural intelligence. Continuum: Journal of Media and Culture 25(6):779-794

Bateson G (1972) Steps to an ecology of mind. Ballantine/Random House, New York

Bellette KJ (2012) Communication is a Two Way Street. Water and Climate: Policy Implementation Challenges, $2^{\text {nd }}$ Practical Responses to Climate Change national conference, 1-3 May 2012. Conference Papers, Engineers Australia, Canberra, file PRCC_Bellette.

DIISR (2011) Environmental Sustainability Expert Working Group submission, Strategic Roadmap for Australian Research Infrastructure Discussion Paper. Department of Industry, Innovation, Science and Research, Canberra. Available at http://www.innovation.gov.au/Science/ResearchInfrastructure/Pages/default.aspx

Shove E (2010) Beyond the ABC: climate change policy and theories of social change. Environment and Planning A 42:1273-1285

Sofoulis Z (2010) Water managers' views on the social dimensions of urban water. Report from CrossConnections: Linking Urban Water Managers with Humanities, Arts and Social Sciences Researchers. Centre for Cultural Research, University of Western Sydney, Parramatta. Available at http://www.uws. edu.au/ics/research/projects/2010.

Sofoulis Z (2011a) Cross-Connections: Linking urban water managers with humanities, arts and social sciences researchers, Waterlines Report Series 60 October 2011, National Water Commission, Canberra. http:// www.nwc.gov.au/publications/waterlines/cross-connections-linking-urban-water-managers-with-humanities,arts-and-social-sciences-researchers2. Summary at http://www.uws.edu.au/ics/research/projects/2010.

Sofoulis Z (2011b) Skirting Complexity: The retarding quest for the average water user. Continuum: Journal of Media and Culture 25(6):795-810

Sofoulis Z, Strengers Y (2011) Healthy engagement: Evaluating models of providers and users for cities of the future. Conference Proceedings, Ozwater'11, annual conference of Australian Water Association, May 9-11, Adelaide 